\title{
Distribution of crustal magnetic fields on Mars: Shock effects of basin-forming impacts
}

\author{
L. L. Hood and N. C. Richmond \\ Lunar and Planetary Laboratory, University of Arizona, Tucson, Arizona, USA
}

E. Pierazzo

Planetary Science Institute, Tucson, Arizona, USA

P. Rochette

University of Aix-Marseille 3, Aix en Provence, France

Received 23 November 2002; revised 24 December 2002; accepted 12 February 2003; published 20 March 2003.

[1] Crustal magnetic fields on Mars are inhomogeneously distributed with the strongest fields occurring over the southern highlands in a longitude sector between approximately $130^{\circ} \mathrm{E}$ and $240^{\circ} \mathrm{E}$. Using analytic approximations and empirical scaling laws, it is estimated that much of the weakly magnetized southern highlands (i.e., that between $110^{\circ} \mathrm{W}$ and $130^{\circ} \mathrm{E}$ ) was shocked to pressures exceeding 1-2 GPa during the Hellas and Argyre impacts. Possible primary remanence carriers in the martian crust include iron oxides and iron sulfides (pyrrhotite). If pyrrhotite is the main remanence carrier, extensive demagnetization of crustal regions $(\sim 90 \%)$ may occur at shock pressures of $2 \mathrm{GPa}$ or more. Thus, at least for this remanence carrier, impact shock demagnetization can potentially explain the distribution of crustal fields in the southern highlands. INDEX TERMS: 5440 Planetology: Solid Surface Planets: Magnetic fields and magnetism; 5420 Planetology: Solid Surface Planets: Impact phenomena (includes cratering); 1540 Geomagnetism and Paleomagnetism: Rock and mineral magnetism. Citation: Hood, L. L., N. C. Richmond, E. Pierazzo, and P. Rochette, Distribution of crustal magnetic fields on Mars: Shock effects of basin-forming impacts, Geophys. Res. Lett., 30(6), 1281, doi:10.1029/2002GL016657, 2003.

\section{Introduction}

[2] To date, comparisons of the distribution of martian crustal magnetic fields (e.g., Figure 1a) with surface geology have revealed several basic characteristics [Acuña et al., 1999, 2001; Connerney et al., 1999; Purucker et al., 2000; Cain et al., 2003]. First, the strongest anomalies occur over the older (Noachian) southern highland terrane and are relatively weak over the younger, resurfaced northern lowlands. Second, a zone of especially strong anomalies occurs in the Southern Hemisphere over Noachian terrane in a longitude sector between approximately $130^{\circ} \mathrm{E}$ and $240^{\circ} \mathrm{E}$. Third, anomalies are especially weak in the near vicinities of the large southern hemisphere impact basins, Hellas and Argyre. Fourth, there exists a partial correlation between magnetic anomalies and valley networks, which are believed to have been caused by surface water erosion [e.g., Harrison and Grimm, 2002].

Copyright 2003 by the American Geophysical Union. 0094-8276/03/2002GL016657
[3] The first characteristic implies that the martian dynamo must have been operative at least during the earliest (Noachian) times [Acuña et al., 1999, 2001] and that the later event that resulted in resurfacing of the northern lowlands must have weakened or eliminated most magnetic anomalies in this region. The interpretation of an early core dynamo is consistent with the observed magnetization of carbonate blebs in ALH84001, dated as older than 3.9 Gyr [Weiss et al., 2002]. Although the origin of the northern lowlands is not well understood, recent interpretations of Mars Global Surveyor (MGS) topography and gravity data have indicated that the northern lowlands are actually as old as the southern highlands [Frey et al., 2002] and that the northern hemisphere was a zone of high heat flow early in martian history [Zuber et al., 2000]. The same data indicate that martian crustal thickness does not correlate with the dichotomy boundary as expected if one or more giant impacts were responsible for the formation of the northern lowlands. These results tend to favor the main alternative model, which hypothesizes that a single mantle convection cell eroded the lower crust in what is now the northern zone of Mars. According to this model, the lowland plains resulted from foundering of the upper crust and later lava flooding and erosion [McGill and Dimitriou, 1990]. The anomalous heat flow and erosion of the lower crust predicted by this model may be sufficient to explain the weakening of pre-existing deep crustal magnetization in this zone.

[4] The second and third characteristics (the concentration of anomalies in the southern hemisphere near the $180^{\circ}$ longitude meridian and the lack of significant anomalies in the near vicinities of Hellas and Argyre) are not so well understood. The formation of the Tharsis uplift and associated volcanic constructs would have thermally demagnetized a substantial portion of the Noachian crust in that region. However, this mechanism alone does not help to explain the predominance of strong anomalies within the $130^{\circ} \mathrm{E}$ to $240^{\circ} \mathrm{E}$ longitude sector in the Southern Hemisphere. Shock demagnetization is a likely cause of the reduced fields near Hellas and Argyre [Acuña et al., 1999; Nimmo and Gilmore, 2001; Mohit and Arkani-Hamed, 2001; Purucker, 2002; Kletetschka et al., 2002]. If strong partial demagnetization extended 2 to 4 basin radii into the surrounding highland terrane, then these impacts could possibly explain much of the reduced crustal field ampli- 
(a)

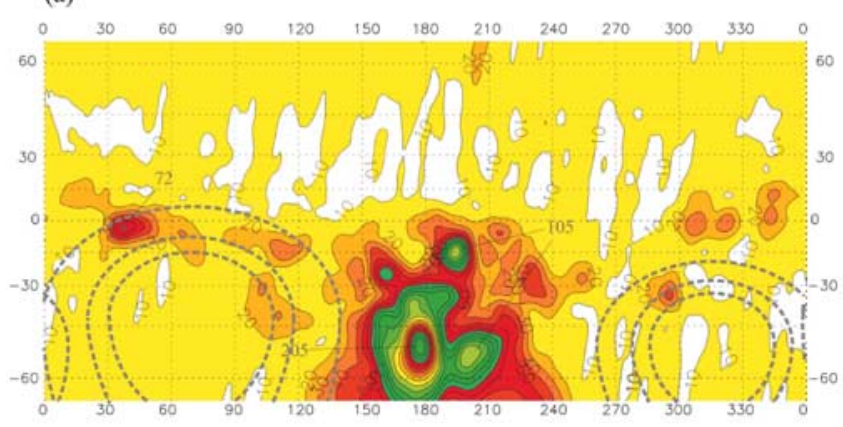

(b)

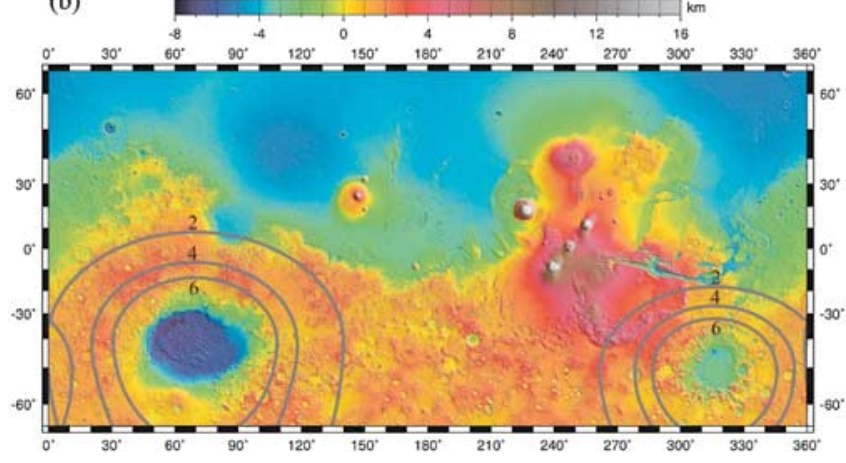

Figure 1. (a) Magnetic field magnitude at the MGS mapping altitude $(380-420 \mathrm{~km})$ produced using methods described by Hood and Zakharian [2001]. The contour interval is $10 \mathrm{nT}$ and the approximate ionospheric noise level is also $\sim 10 \mathrm{nT}$. (b) Topographic map of Mars (Mercator projection courtesy MOLA science team). The contours indicate peak shock pressures (GPa) during the Hellas (left) and Argyre (right) impacts estimated analytically (see the text). The red area near $250^{\circ} \mathrm{E}$ is the region of the Tharsis uplift.

tudes in the southern hemisphere outside of the $130^{\circ} \mathrm{E}$ to $240^{\circ} \mathrm{E}$ longitude sector. In support of the latter possibility, demagnetization signatures of impact craters on the Moon with radii $>50 \mathrm{~km}$ are observed to extend to $\sim 2-4$ crater radii [Halekas et al., 2002].

[5] The fourth characteristic suggests that magnetization in the deep martian crust may have been stimulated in part by hydrothermal circulation that also led to erosive formation of surface valley networks [Harrison and Grimm, 2002]. However, valley networks are widely distributed in longitude and are equally numerous in both hemispheres (see Figure 10 of their paper). Therefore, this mechanism can not explain the concentration of strong anomalies in the $130^{\circ} \mathrm{E}$ to $240^{\circ} \mathrm{E}$ longitude sector (Figure 1a).

[6] In this paper, we report simplified analytic calculations intended to investigate more quantitatively whether radially extended shock demagnetization associated with the Hellas and Argyre impacts may be sufficient to explain the inhomogeneous distribution of crustal fields in the southern highlands.

\section{Approximate Models for Shock Pressure Decay}

[7] A simple approximation of shock pressure decay with radial distance can be obtained using an empirical determi- nation of particle velocity decay and the Hugoniot equations [e.g., Melosh, 1989, p. 66]:

$$
P(r)=\rho_{\circ t}\left[C_{t}+S_{t} u_{\circ}\left(r_{\circ} / r\right)^{1.87}\right] u_{\circ}\left(r_{\circ} / r\right)^{1.87}
$$

where $\rho_{\circ t}$ is the unshocked target mass density, $u_{\circ}$ is the initial particle velocity at distance $r_{\circ}$ from the impact point, and $C_{t}, S_{t}$ are empirically determined shock parameters [Melosh, 1989]. Near the surface, the peak shock pressure $P\left(r_{\circ}\right)$ is roughly constant for $r_{\circ} \leq r_{p}$, the projectile radius, and close to that calculated by the planar impact approximation [Ahrens and O'Keefe, 1977] (see Pierazzo et al. [1997, Figure 7] for a two-dimensional view of the region of validity of the planar impact approximation). Using the planar impact approximation, Ahrens and O'Keefe [1977] estimated peak particle velocities of 3.75 and $7.5 \mathrm{~km} / \mathrm{s}$ for a gabbroic anorthosite projectile impacting on a gabbroic anorthosite target at 7.5 and $15 \mathrm{~km} / \mathrm{s}$ respectively. Substituting $x$ for $\left(r_{\circ} / r\right)^{1.87}$, (1) becomes a simple quadratic equation, that can then be solved for the normalized radial distance at which the shock pressure is equal to a given $P_{1}$. For example, for $P_{1}=2 \mathrm{GPa}$, this gives $r / r_{\circ}=8.8$ for a $7.5 \mathrm{~km} / \mathrm{s}$ impact, and $r / r_{\circ}=12.7$ for a $15 \mathrm{~km} / \mathrm{s}$ impact. Here, we have used $\rho_{\mathrm{o} t}=3.965 \mathrm{~kg} / \mathrm{m}^{3}, C_{t}=7.71 \mathrm{~km} / \mathrm{s}$ and $S_{t}=1.05$ for a gabbroic anorthosite (high pressure phase) composition [Melosh, 1989, Table 4.2]. The chosen range of impact velocities reflects the most probable range of velocities of near-Earth asteroids that cross the orbit of Mars [see, e.g., Bottke et al., 1994, Figure 9].

[8] To convert these relative distance estimates to absolute distances from the centers of the Hellas and Argyre basins, it is necessary to estimate the radii of impactors that could have produced these basins. This can be done using the $\pi$-scaling law [Schmidt and Housen, 1987], once we obtain an estimate of the structures' transient diameters. Transient crater diameter is defined as the size of the precollapse bowl-shaped crater opened up by the impact. Their determination in complex craters, especially potential multiring (or at least peak ring) ones like Hellas and Argyre, is not as straightforward as in simple craters [see, e.g., Melosh, 1989]. Geophysical and theoretical studies of the buried Chicxulub structure [Morgan et al., 2000; Collins et al., 2002] have identified a peak ring, $D \sim 80 \mathrm{~km}$, a crater rim, $D \sim 150 \mathrm{~km}$, and possibly two other outer rings with $D \sim$ $200 \mathrm{~km}$ and $D \sim 250 \mathrm{~km}$. The currently accepted transient crater diameter for Chicxulub is around $100 \mathrm{~km}$ [Morgan et al., 1997]; that places it between the peak ring and the crater rim, i.e., slightly outside the innermost topographic boundaries of the structure. Assuming that the transient crater diameter coincides with the inner topographic boundaries (based on MOLA data; Figure 1b) of the Hellas and Argyre basins, $\sim 1400$ and $\sim 1000 \mathrm{~km}$, respectively, one obtains a projectile diameter between 685 and $463 \mathrm{~km}$ for Hellas, and between 445 and $301 \mathrm{~km}$ for Argyre, for impact velocitites between 7.5 and $15 \mathrm{~km} / \mathrm{s}$. (For these calculations we used the impact scaling code developed by H.J. Melosh, available at www.lpl.arizona.edu/tekton/crater.html; other input parameters used are: $2900 \mathrm{~kg} / \mathrm{m}^{3}$ for impactor and target density (appropriate for a low pressure phase gabbroic anorthosite composition); $3.72 \mathrm{~m} / \mathrm{s}^{2}$ for the acceleration of gravity; $45^{\circ}$ for most probable impact angle.) Thus, the 2 GPa shock pressure is reached between 2940 and $3000 \mathrm{~km}$ from the center for a 7.5 to $15 \mathrm{~km} / \mathrm{s}$ Hellas-forming 
impactor, and between 1911 and $1949 \mathrm{~km}$ away for an Argyre-forming impactor. The resulting radial distances do not appear to depend strongly on impact velocity (although the latter does affect the magnitude of the shock for $r_{\circ} \leq r_{p}$ ), but they scale with transient crater size (i.e., with the impact energy). In Figure 1b, the inner contours represent the mean distance from the structure's center at which the peak shock pressure should have reached approximately $6 \mathrm{GPa}$ plotted on the MOLA Mercator projection. The $4 \mathrm{GPa}$ and $2 \mathrm{GPa}$ contour lines are similarly shown in Figure 1b. To simplify comparisons with the magnetic field distribution, the pressure contours are also replotted in Figure 1a.

\section{Remanence Carriers and Shock Demagnetization}

[9] Based in part on studies of shergotite, nakhlite, and chassignite (SNC) meteorites, several candidate crustal remanence carriers on Mars have been proposed. These include iron oxides (titanomagnetite, hematite [Hargraves et al., 1977; Collinson, 1986; Cisowski, 1986; Kletetschka et al., 2000; Robinson et al., 2002]) and iron sulfides (monoclinic pyrrhotite [Rochette et al., 2001, 2002]). Titanomagnetite is the main magnetic carrier in a number of SNC meteorites, including Los Angeles, which has the strongest observed saturation remanent magnetization [e.g., Rochette et al., 2001]. However, an important problem with this carrier is its low Curie temperature $\left(150^{\circ} \mathrm{C}\right)$, which would inhibit magnetization at depths of more than $\sim 10 \mathrm{~km}$ during early martian history. In contrast, studies of martian magnetic spectra as well as the absence of demagnetization signatures for smaller craters suggest depths for martian magnetic anomaly sources of up to 30-50 km [Voorhies et al., 2002; Nimmo and Gilmore, 2001; P. S. Mohit and J. Arkani-Hamed, personal communication, 2002]. Hematite has a much higher Curie temperature but this mineral has not been detected in any SNC meteorite and its presence as inferred from the TES instrument on MGS [Christiansen et al., 2000] does not require existence at depth in the crust. Recently, Robinson et al. [2002] have proposed that terrestrial rocks containing finely exsolved lamellae of hematite-ilmenite $\left(\mathrm{Fe}_{2} \mathrm{O}_{3}-\right.$ $\mathrm{FeTiO}_{3}$ ) may suggest an explanation for magnetic anomalies such as those found on Mars. In addition, it is possible that martian rocks may undergo magnetite-ilmenite exsolution [e.g., Nimmo, 2000]. Finally, pyrrhotite $\left(\mathrm{Fe}_{7} \mathrm{~S}_{8}\right)$ has recently been advocated by Rochette et al. [2001, 2002]. According to their analysis, pyrrhotite is the main carrier in more than half of the SNC meteorites, including most of the basaltic shergottites, which may constitute the most likely analog for average martian crustal composition. They also point out that sulfides are expected to be more common in martian crustal rocks because of the higher iron content of martian basalts and because of the large concentration of sulfur in martian soils. They note that the Curie temperature of pyrrhotite $\left(325^{\circ} \mathrm{C}\right)$ is sufficiently high to allow magnetization of a substantial depth range of the crust, although perhaps not at depths of $40-50 \mathrm{~km}$ where the deepest sources are inferred to be located. Thus, this mineral must be regarded as another candidate primary remanence carrier in the martian crust.

[10] If iron oxides are assumed to be the primary magnetic remanence carriers, then results of shock demagnetization experiments on terrestrial basalt samples [Hargraves and
Perkins, 1969; Pohl et al., 1975; Cisowski and Fuller, 1978] should be approximately applicable to the martian case. For example, the experiments of Pohl et al. [1975] show that shock demagnetization of titanomagnetite grains is effective mainly for those grains with low coercivities (stability against alternating field demagnetization). Shock stresses of $0.25 \mathrm{GPa}$ are sufficient to demagnetize such grains with coercivities of 5 to $10 \mathrm{mT}$ while stresses of $0.8 \mathrm{GPa}$ are sufficient to demagnetize grains with coercivities of 15 to 20 $\mathrm{mT}$. However, the remanent coercivities of SNC meteorites containing titanomagnetite remanence carriers range from 55 to $63 \mathrm{mT}$ [e.g., Rochette et al., 2001, Table 1]. It is therefore likely that much larger shock stresses would be needed to demagnetize these samples if titanomagnetite is the main remanence carrier. Experiments by Hargraves and Perkins [1969] on terrestrial samples containing homogeneous magnetite as the main magnetic phase indicate that shock pressures $>5 \mathrm{GPa}$ are necessary to significantly reduce the remanence intensity. Unfortunately, to our knowledge, no experimental data are available on shock demagnetization of rocks containing hematite-ilmenite lamellae. If, on the other hand, high-coercivity monoclinic pyrrhotite is assumed to be the main remanence carrier, then nearly complete demagnetization is expected at pressures near $2.7 \mathrm{GPa}$ [Rochette et al., 2002; see also Vaughan and Tossell, 1973]. A pyrrhotitebearing sample shows a decrease of $58 \%$ of its initial remanence after compression to $1 \mathrm{GPa}$ at room temperature. Hence, extensive $(\sim 90 \%)$ demagnetization is expected at pressures of order 2 GPA and significant $(\sim 50 \%)$ partial demagnetization occurs at pressures of $1 \mathrm{GPa}$ or less.

\section{Discussion}

[11] Results of the approximate peak shock pressure calculations shown in Figure 1b suggest that the inhomogeneous distribution of crustal magnetization in the martian southern highlands (Figure 1a) can potentially be attributed to impact shock demagnetization. For example, if pyrrhotite is assumed to be the major remanence carrier in the martian crust, then extensive ( $90 \%)$ demagnetization may be expected within 3-4 basin radii. More detailed calculations, including three-dimensional numerical simulations, are needed to determine the actual spatial shock distribution (as a function of depth as well as radial distance) beneath these basin-forming impacts for a variety of impact angles, azimuths, and impactor compositions. However, results of the present first-order calculations indicate that most anomalies within a few basin radii of Hellas and Argyre would have been eliminated or greatly weakened by impact shock waves. Only a few anomalies (e.g., that near $290^{\circ} \mathrm{E}$, $35^{\circ} \mathrm{S}$ ) partly survived the shock event owing perhaps to greater depths or higher coercivities of source materials.

[12] A remaining large source of uncertainty in the analysis is the undetermined identity of the primary martian crustal remanence carrier(s) together with the lack of complete data on shock demagnetization of crustal rocks containing these carriers. As noted above, while limited experimental data are available for pyrrhotite, it is unclear whether the lower Curie temperature of this mineral is consistent with the inferred presence of at least some martian anomaly sources at large depths in the crust [e.g., Nimmo and Gilmore, 2001; Voorhies et al., 2002]. On the 
other hand, while candidate remanence carriers with higher Curie temperatures have been proposed, shock pressure demagnetization data are either sparse or non-existent for these minerals. Thus, final conclusions about the role of impact shock in producing the gross distribution of martian crustal fields must await (a) a better knowledge of martian remanence carriers at depth in the crust; and (b) detailed shock demagnetization data for these carriers.

[13] Acknowledgments. We thank J. Halekas, H. J. Melosh, and J. Arkani-Hamed for helpful discussions. Criticisms by two anonymous reviewers significantly improved the paper. Supported by a grant from the NASA Mars Data Analysis Program.

\section{References}

Acuña, M., et al., Global distribution of crustal magnetization discovered by the Mars Global Surveyor MAG/ER experiment, Science, 284, 790 793, 1999.

Acuña, M., et al., The magnetic field of Mars: Summary of results from the aerobraking and mapping orbits, J. Geophys. Res., 106, 23,403-23,417, 2001.

Ahrens, T. J., and J. D. O'Keefe, Equations of state and impact-induced shock-wave interaction on the Moon, in Impact and Explosion Cratering, edited by D. J. Roddy, R. Pepin, and R. Merrill, pp. 639-656, Pergamon, New York, 1977.

Bottke, W., Jr., M. Nolan, R. Greenberg, and R. Kolvoord, Collisional lifetimes and impact statistics of near-Earth asteroids, in Hazards Due to Comets and Asteroids, edited by T. Gehrels, pp. 337-358, Univ. of Ariz. Press, Tucson, 1994.

Cain, J. C., B. Ferguson, and D. Mozzoni, An $n=90$ An internal potential function of the Martian crustal magnetic field, J. Geophys. Res., 108(E2), 5008, doi:10.1029/2000JE001487, 2003.

Christiansen, P. R., et al., Detection of localized crystalline hematite on Mars from the thermal emission spectrometer investigation: Evidence for near-surface water, J. Geophys. Res., 105, 9623-9642, 2000.

Cisowski, S. M., Magnetic studies on Shergotty and other SNC meteorites, Geochim. Cosmochim. Acta, 50, 1043-1048, 1986.

Cisowski, S. M., and M. Fuller, The effect of shock on the magnetism of terrestrial rocks, J. Geophys. Res., 83, 3441-3458, 1978.

Collins, G. S., H. J. Melosh, J. V. Morgan, and M. R. Warner, Hydrocode simulations of Chicxulub crater collapse and peak-ring formation, Icarus, 157, 24-33, 2002.

Collinson, D. W., Magnetic properties of Antarctic shergottite meteorites EETA 79001 and ALHA 77005: Possible relevance to a martian magnetic field, Earth Planet. Sci. Lett., 77, 159-164, 1986.

Connerney, J. E. P., M. Acuña, P. Wasilewski, N. Ness, H. Rème, C. Mazelle, D. Vignes, R. Lin, D. Mitchell, and P. Cloutier, Magnetic lineations in the ancient crust of Mars, Science, 284, 794-798, 1999.

Frey, H., J. Roark, K. Shockey, E. Frey, and S. E. H. Sakimoto, Ancient lowlands on Mars, Geophys. Res. Lett., 29(10), 1384, doi:10.1029/ 2001GL013832, 2002.

Halekas, J. S., D. Mitchell, R. Lin, L. Hood, M. Acuña, and A. Binder, Demagnetization signatures of lunar impact craters, Geophys. Res. Lett., 29(13), 1645, doi:10.1029/2001GL013924, 2002.

Hargraves, R., and W. Perkins, Investigations of the effect of shock on natural remanent magnetism, J. Geophys. Res., 74, 2576-2589, 1969.

Hargraves, R. B., D. W. Collinson, R. E. Arvidson, and C. R. Spitzer, The Viking magnetic properties experiment: Primary mission results, J. Geophys. Res., 82, 4547-4558, 1977.

Harrison, K. P., and R. E. Grimm, Controls on Martian hydrothermal systems: Application to valley network and magnetic anomaly formation, J. Geophys. Res., 107(E5), 5025, doi:10.1029/2001JE001616, 2002.

Hood, L., and A. Zakharian, Mapping and modeling of magnetic anomalies in the northern polar region of Mars, J. Geophys. Res., 106, 14,601$14,619,2001$.
Kletetschka, G., P. J. Wasilewski, and P. T. Taylor, Mineralogy of the sources for magnetic anomalies on Mars, Meteorit. Planet. Sci., 35, $895-899,2000$

Kletetschka, G., J. E. Connerney, P. J. Wasilewski, and M. H. Acuña, Shock demagnetization of martian crust, Eos Trans. $A G U, 83$, Spring Meet. Suppl., P32A-04, 2002.

McGill, G., and A. Dimitriou, Origin of the Martian global dichotomy by crustal thinning in the late Noachian or early Hesperian, J. Geophys. Res., $95,12,595-12,605,1990$.

Melosh, H. J., Impact Cratering: A Geologic Process, 245 pp., Oxford Univ. Press, New York, 1989.

Mohit, P. S., and J. Arkani-Hamed, Demagnetization of martian crust by large impacts, Eos Trans. $A G U, 82$, Fall Meet. Suppl., P42A-0549, 2001.

Morgan, J. V., et al., Size and morphology of the Chicxulub impact crater, Nature, 390, 472-476, 1997.

Morgan, J. V., M. R. Warner, G. S. Collins, H. J. Melosh, and G. L. Christeson, Peak-ring formation in large impact craters: Geophysical constraints from Chicxulub, Earth Planet. Sci. Lett., 183, 347-354, 2000.

Nimmo, F., Dike intrusion as a possible cause of linear martian magnetic anomalies, Geology, 28, 391-394, 2000.

Nimmo, F., and M. S. Gilmore, Constraints on the depth of magnetized crust on Mars from impact craters, J. Geophys. Res., 106, 12,315$12,323,2001$.

Pierazzo, E., A. M. Vickery, and H. J. Melosh, A reevaluation of impact melt production, Icarus, 127, 408-423, 1997.

Pohl, J., U. Bleil, and U. Horenmann, Shock magnetization and demagnetization of basalt by transient stress up to $10 \mathrm{kbar}, J$. Geophys. Res., 41, $23-41,1975$.

Purucker, M., Why are some martian terranes strongly magnetic and some non-magnetic?, Lunar Planet Sci., XXXIII, 1936, 2002.

Purucker, M., D. Ravat, H. Frey, C. Voorhies, T. Sabaka, and M. Acuña, An altitude-normalized magnetic map of Mars and its interpretation, Geophys. Res. Lett., 27, 2449-2452, 2000.

Robinson, P., R. J. Harrison, S. A. McEnroe, and R. B. Hargraves, Lamellar magnetism in the haematite-ilmenite series as an explanation for strong remanent magnetization, Nature, 418, 517-520, 2002

Rochette, P., J.-P. Lorand, G. Fillion, and V. Sautter, Pyrrhotite and the remanent magnetization of SNC meteorites: A changing perspective on martian magnetism, Earth Planet. Sci. Lett., 190, 1-12, 2001.

Rochette, P., V. Sautter, F. Brunet, V. Chevrier, and J. P. Lorand, Matching Martian magnetic anomalies and SNC magnetic properties, Lunar Planet. Sci., XXXIII, 1199, 2002.

Schmidt, R. M., and K. R. Housen, Some recent advances in the scaling of impact and explosion cratering, Int. J. Impact Eng., 5, 543-560, 1987.

Vaughan, D. J., and J. A. Tossell, Magnetic transitions observed in sulfide minerals at elevated pressures and their geophysical significance, Science, 179, 375-377, 1973

Voorhies, C. V., T. J. Sabaka, and M. Purucker, On magnetic spectra of Earth and Mars, J. Geophys. Res., 107(E6), 5034, doi:2001JE001534, 2002 .

Weiss, B. P., V. Hojatollah, F. J. Baudenbacher, J. L. Kirschvink, S. T. Stewart, and D. L. Shuster, Records of an ancient Martian magnetic field in ALH84001, Earth Planet Sci. Lett., 201, 449-463, 2002.

Zuber, M. T., et al., Internal structure and early thermal evolution of Mars from Mars Global Surveyor topography and gravity, Science, 287, 17881793,2000 .

L. L. Hood and N. C. Richmond, Lunar and Planetary Laboratory, University of Arizona, 1629 E. University Blvd., Tucson, AZ 85721, USA. (lon@lpl.arizona.edu)

E. Pierazzo, Planetary Science Institute, 620 N. 6th Ave., Tucson, AZ 85705, USA. (betty@psi.edu)

P. Rochette, University of Aix-Marseille 3, BP 80, Europôle de 1'Arbois, 13545 Aix en Provence Cedex 4, France. (rochette@cerege.fr) 